\title{
Feira E-Lixo: projeto de ensino multidisciplinar envolvendo re-uso de lixo eletrônico
}

\author{
Ana Elisa Ferreira Schmidt ${ }^{1}$, Mozara Dias Koehler ${ }^{1}$ \\ ${ }^{1}$ Instituto Federal Catarinense - Campus Camboriú (IFC) \\ Caixa Postal 2016 - 88340-055 - Camboriú - SC - Brasil \\ \{anaelisa, mozara\} @ifc-camboriu.edu.br
}

\begin{abstract}
This paper presents the E-Waste Fair, an educational project that proposes a multidisciplinary science fair event involving high school and technical college students whose projects must use electronic waste components, e-waste. The projects presented at the fair should target teaching-learning contents of high school disciplines or technology. The EWaste Fair aims to stimulate student's awareness for proper disposal and reuse of electronic components at the same time it encourages creativity, innovative spirit and integration of knowledge from different disciplines.
\end{abstract}

Resumo. Este artigo apresenta o projeto de ensino da Feira E-Lixo que propõe a realização de uma feira científica multidisciplinar com alunos do ensino médio técnico onde os trabalhos apresentados devem envolver componentes de lixo eletrônico, e-lixo. Os trabalhos apresentados na feira devem privilegiar o ensino-aprendizado de conteúdos de disciplinas do ensino médio ou de tecnologia. A Feira E-Lixo tem por finalidade estimular nos estudantes a conscientização para o descarte adequado e re-uso de componentes eletrônicos ao mesmo tempo que incentiva a criatividade, espírito inovador e integração de conhecimentos adquiridos em diferentes disciplinas.

\section{Introdução}

A rápida obsolescência dos equipamentos eletrônicos tem gerado um grande problema para o meio ambiente e sociedade: o consumismo gera lixo. Nos últimos dez anos, a população do Brasil aumentou 9,65\%, enquanto que, no mesmo período, o volume de lixo cresceu mais do que o dobro disso, 21\%. Esta enorme geração de lixo, entretanto, não é acompanhada de um descarte adequado. De acordo com dados da Associação Brasileira de Empresas de Limpeza Pública e Resíduos Especiais [Abrelpe, 2016], só em 2012, dos 64 milhões de toneladas de resíduos produzidos pela população, 24 milhões (37,5\%) foram enviados para destinos inadequados [OECO, 2014].

O descarte inadequado de lixo é prejudicial à saúde pública e danoso ao meio ambiente. A fim de enfrentar as consequências sociais, econômicas e ambientais do manejo de resíduos sólidos sem prévio e adequado planejamento técnico, a Lei no 12.305/10 [Brasil, 2010] instituiu a Política Nacional de Resíduos Sólidos (PNRS), regulamentada pela Decreto 7.404/10 [Brasil, 2010]. Esta política propõe a prática de 
hábitos de consumo sustentável e contém instrumentos variados para propiciar o incentivo à reciclagem $\mathrm{e}$ à reutilização dos resíduos sólidos (reciclagem $\mathrm{e}$ reaproveitamento), bem como a destinação ambientalmente adequada dos dejetos [OECO, 2014].

O lixo eletro- eletrônico ou e- lixo é o resíduo material produzido pelo descarte de equipamento eletrônico, entre eles computadores, celulares, eletrodomésticos ou televisões. O descarte inadequado do lixo eletrônico (e-lixo) pode causar um grande impacto ambiental porque tem elementos químicos como arsênio, cobre, alumínio, cádmio, mercúrio, chumbo e berílio que, se entrarem em contato com o solo, podem penetrar até o lençol freático e gerar a contaminação de plantas e animais por meio da água [Mattos, 2008]. Segundo a ONUBr - Nações Unidas no Brasil [ONUBr, 2015] atualmente são gerados aproximadamente 41 milhões toneladas de lixo eletrônico por ano no mundo e entre $60 \%$ e $90 \%$ são comercializados ilegalmente ou jogados no lixo.

Dentro da proposta apoiar e disseminar a ideia de novo uso para materiais que não serão mais usados em sua forma original, vê-se nas feiras de ciências uma possibilidade conscientização sobre o tema. Assim, surge a proposta da realização de uma feira de ciências multidisciplinar onde o lixo eletrônico deve ser utilizado na elaboração dos trabalhos a serem apresentados. Entende-se a proposta da feira como um projeto de ensino onde a realização do evento amplia o processo ensino-aprendizagem para além da sala de aula, permitindo inclusive que a comunidade externa participe e aprecie os trabalhos desenvolvidos pelos alunos participantes da feira.

Segundo Mezzari (2011) a exposição dos trabalhos em uma feira multidisciplinar à comunidade auxilia na formação do aluno como ser humano integral, com possibilidades de desenvolverem-se nas mais diversas áreas do conhecimento, não se limitando a uma ou outra competência privilegiada. Segundo a lei 11.892 [Brasil, 2008], os Institutos Federais têm por finalidade e característica: realizar e estimular a pesquisa aplicada, a produção cultural, o empreendedorismo, o cooperativismo e o desenvolvimento científico e tecnológico. Esta característica propicia um ambiente muito favorável ao desenvolvimento de projetos com aplicação prática.

\section{Projeto de Ensino: Feira E-Lixo}

O evento da Feira de Ciências E-lixo teve sua primeira edição realizada no IFCCamboriú em 2015, dentro do Encontro de Tecnologia da Informação. Os principais objetivos deste projeto de ensino são: promover o desenvolvimento da criatividade e da capacidade inventiva e investigativa dos estudantes; incentivar a atividade científica, através da elaboração e execução de projetos científicos multidisciplinares, auxiliando, assim, na construção e consolidação do conhecimento; estimular o aproveitamento dos resíduos tecnológicos.

Para execução dos projetos apresentados na feira, os grupos devem ser formados por no máximo 3 alunos da instituição, de qualquer curso de nível médio, e um professor orientador (não obrigatório). As propostas devem ter como matéria prima principal o lixo eletrônico e devem se enquadrar nas modalidades: Inovação/Invenção 
ou Faça Você Mesmo (Do It Yourself - DIY), onde em cada uma destas modalidade tem-se as categorias: ensino-aprendizagem ou tecnologia.

A modalidade Inovação/Invenção aceita propostas novas ou reformulações de um projeto já existente. No Faça Você Mesmo as propostas podem desenvolver projetos já existentes em tutoriais largamente disponíveis através de sites na internet como Manual do Mundo e Brincando com Robson Sato [Thenório, 2008; Sato, 2015].

Além da elaboração do projeto proposto em si, cada grupo de alunos deve produzir um vídeo-tutorial que explica os fundamentos teóricos e os passos para elaboração do seu projeto. Este vídeo, que deve ser publicado no YouTube pelo grupo, é avaliado por cada avaliador da Feira E-Lixo e considerado na classificação final dos vencedores em cada categoria. Além da prévia avaliação dos vídeos, os trabalhos são expostos para os avaliadores e para a comunidade acadêmica durante o evento da Feira E-Lixo. Os melhores trabalhos de cada modalidade/categoria são premiados com medalhas e brindes, além do recebimento de certificado de participação e exposição dos vídeos produzidos para cada projeto em canal aberto do YouTube.

\section{Feira E-Lixo 2015: resultados alcançados}

Para a realização do evento foi realizada uma campanha de coleta de e-lixo, que arrecadou $298 \mathrm{~kg}$ de lixo eletrônico que, além de serem utilizados nos projetos da feira, foram utilizados em outros projetos do IFC-CAM. O e-lixo que não foi utilizado foi encaminhado à cooperativa de reciclagem.

Durante o evento foram apresentados 07 trabalhos, com 19 alunos envolvidos dos cursos Técnico em Informática e Técnico em Controle Ambiental, cuja matéria prima principal foi o lixo eletrônico, tendo seus vídeos publicados no canal aberto da Feira E-Lixo no YouTube [E-Lixo 2015]. A elaboração dos trabalhos envolveu conhecimentos adquiridos em disciplinas como física, matemática, instalações elétricas, eletrônica, hardware, algoritmos, programação avançada, projeto de interfaces, dentre outras. A figura 1 mostra momentos da feira.
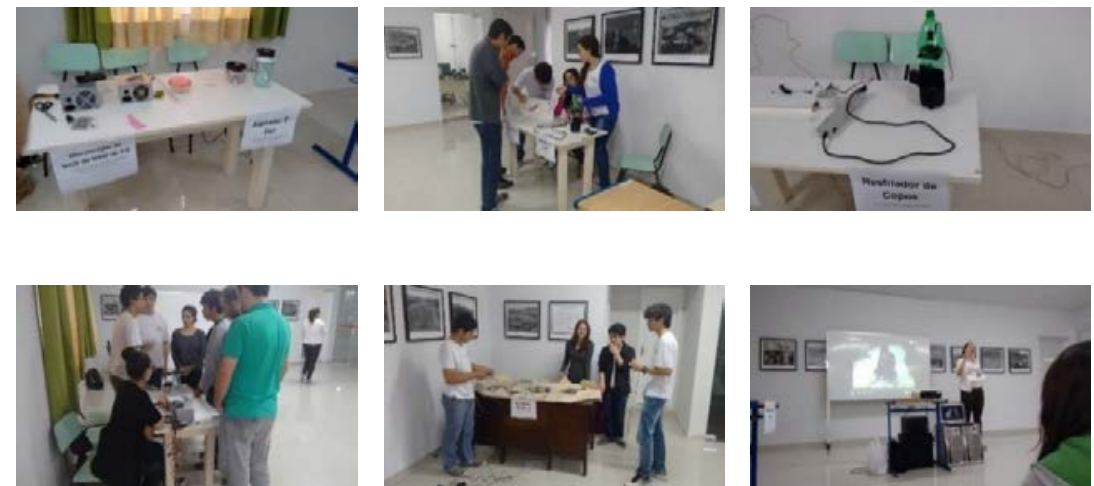

Figura 1. Momentos da Feira de Ciências E-Lixo 2015.

O trabalho "Desenvolvimento de um Aspirador de Pó para Teclado", teve artigo aceito no $4^{\circ}$ Concurso de Trabalhos Técnicos em Informática no Computer on the Beach 2016 [COTB, 2016]. 


\section{Referências}

Abrelpe. Associação Brasileira de Empresas de Limpeza Pública e Resíduos Especiais. http://www.abrelpe.org.br/. Março 2016.

Brasil. Lei No 12.305, de 2 de agosto de 2010. Institui a Política Nacional de Resíduos Sólidos Brasília. http://w ww.planalto.gov.br/ccivil_03/_ato20072010/2010/lei/112305.htm. Março 2016.

Brasil. Decreto No 7.404, de 23 de dezembro de 2010. Regulamenta a Lei no 12.305, de 2 de agosto de 2010, que institui a Política Nacional de Resíduos Sólidos, cria o Comitê Interministerial da Política Nacional de Resíduos Sólidos e o Comitê Orientador para a Implantação dos Sistemas de Logística Reversa. Brasília. http://www.planalto.gov.br/ccivil_03/_ato2007-2010/2010/Decreto/D7404.htm. Março 2016.

Brasil. Lei $\mathrm{N}^{0}$ 11.892, de 29 de janeiro de 2008. Institui A Rede Federal de EducaçãoProfissional, Científica e Tecnológica, Cria Os Institutos Federais de Educação, Ciência e Tecnologia, e Dá Outras Providências. Brasília. http://www.planalto.gov.br/ccivil_03/_ato2007-2010/2008/lei/111892.htm. Março 2016.

COTB. Computer on the 2016. http://www.computeronthebeach.com.br/portal/programacao/concurso-de-trabalhostecnicos-2016. Março 2016.

E-Lixo. Feira de Ciências E-Lixo 2015 do Instituto Federal Catarinense - Campus Camboriú. Vídeos dos trabalhos apresentados. https://www.youtube.com/channel/UCVxF4xI9O7kcKsndxPdGuqQ. Março 2016.

Thenório, Iberê; Fulfaro, Mari. Manual do mundo. 2008. http://www.manualdomundo.com.br. Março 2016.

Mattos, K. M. da C.; Mattos, K. M. da C.; Perales, W. J. S. Os impactos ambientais causados pelo lixo eletrônico e o uso da logística reversa para minimizar os efeitos causados ao meio ambiente. 2008. http://www.abepro.org.br/biblioteca/enegep2008_TN_STP_077_543_11709.pdf. Março 2016.

Mezzari, S.; Frota, P. R. de O.; Martins, M, da C. Feiras multidisciplinares e o ensino de Ciências. Revista Electrónica de Investigación y Docencia, n.1, p. 107-119, 2011.

OECO, Associação O Eco. Entenda a Política Nacional de Resíduos Sólidos. Julho, 2014. http://www.oeco.org.br/dicionario-ambiental/28492-entenda-a-politicanacional-de-residuos-solidos/. Março 2016.

ONUBr- Nações Unidas no Brasil. 2015. https://nacoesunidas.org/onu-preve-quemundo-tera-50-milhoes-de-toneladas-de-lixo-eletronico-em-2017/. Março 2016.

SATO, Robson. Brincando com Robson Sato. 2015. http://www.brincandocomrobsonsato.com.br/. Março 2016. 